\title{
Influence of material models on quality of results of plastic parts' mechanical analyses
}

\author{
Wpływ modeli materiałowych na jakość wyników analiz \\ wytrzymałościowych wyrobów z tworzyw sztucznych
}

\author{
PRZEMYSŁAW POSZWA \\ PAWEK BRZĘK \\ MAREK SZOSTAK *
}

DOI: https://doi.org/10.17814/mechanik.2017.12.205

\begin{abstract}
The influence of simplified and expanded material model on stress and strain in plastic parts was presented. Because of nonlinear properties the prediction of the behavior of plastic parts is difficult. In this work it was shown what simplifications should be used with linear material model for fiber-filled plastics.

KEYWORDS: plastics, postmoulding properties, Ramberg-Osgood model
\end{abstract}

Nowadays, more and more elements originally made of metal are replaced with plastic parts. This is due to the low density of polymer materials, their high relative strength, as well as the ease of forming (complicated elements can be produced in one operation).

The disadvantages of plastics are low rigidity and very non-linear material properties. To increase rigidity, a glass fiber filler is used above all. Its addition to the polymer allows to increase the rigidity from four to six times (depending on the type and amount of fiber added, in the case of carbon fiber, it is possible to achieve up to 10-fold improvement in rigidity), due to which the manufactured elements have less deformability with a slight increase in basis weight [1,2]. The disadvantage of using glass fibers is to reduce the maximum elongation of details and their impact strength. In addition, the introduction of glass fibers into the polymer matrix results in the anisotropy of the material depending on the orientation of the fiber, which in turn depends on the method of filling the cavity forming the mold. In addition, it complicates the mathematical description of the phenomenon of deformation under the influence of applied loads.

\section{Material models}

The basic mathematical model used in engineering practice is Hooke's law $(\sigma=E \varepsilon)$, describing the linear relationship between stress $\sigma$ (in $\mathrm{MPa}$ ) and strain $\varepsilon$ [3]. This model only fits materials the rigidity modulus $E$ (in $\mathrm{MPa}$ ) of which does not change, and deformations are

\footnotetext{
* Mgr inż. Przemysław Poszwa (przemyslaw.b.poszwa@doctorate.put.poznan.pl), mgr inż. Paweł Brzęk (pawel.brzek@put.poznan.pl), dr hab. inż. Marek Szostak prof. PP (marek.szostak@put.poznan.pl) - Instytut Technologii Materiałów Politechniki Poznańskiej
}

small (do not exceed 5\%). In the case of plastics, this relationship is approximately linear in a very narrow range, therefore the use of this model results in clear deviations at higher loads.

The relationship between stress and strain for plastics is well described by the Ramberg-Osgood (RO) model. It is expressed as follows [4]:

$$
\epsilon_{m}=\epsilon_{m}^{e}+\epsilon_{m}^{p}=\frac{\sigma_{m}}{E_{m}}+\left(\frac{\sigma_{0}}{E_{m}}\right)\left(\frac{\sigma_{m}}{\sigma_{0}}\right)^{n}
$$

where: $\sigma_{m}$ - stress, $\sigma_{m}$ - yield point, $\mathrm{n}$ - exponent of power law, $E_{m}$ - modulus of warp stiffness, $\epsilon_{m}^{e}, \epsilon_{m}^{p}$ equivalent strain - respectively - elastic and plastic.

This non-linear model was created in 1943 to describe materials, in which plastic deformation occurs with a smooth transition between elastic and plastic deformation [5]. For this reason, it is often used for polymeric materials.

\section{Description of experiment}

Autodesk Nastran In-CAD 2018.1 was used in conjunction with Autodesk Helius PFA 2018.1 to predict the behavior of plastic moldings under load. The first software is a tool for mechanical analysis, the second allows to extend the capabilities of the former to include the repetitive properties of plastics along with their nonlinearity.

In order to take into account the impact of processing on mechanical properties, injection molding was first performed in Autodesk Moldflow Insight Standard 2018.1. The results have been coupled with a mechanical analysis program via a module found in Autodesk Helius (called the Advanced Material Exchange). It allows transferring information about fiber orientation, deformation of the compact, strength of the connection line and conditions of destruction of the compact to the structural analysis program [6].

Two examples were used - a material test rig in accordance with ASTM D638-10 and a brake pedal. In both cases, the same type of material was used - Tenacc polyol T14066 and T14067 (with 25 and 35 percent glass fiber content - referred to as: POM25 and POM35) to show the sensitivity of the results to the reinforcing fiber. Material characteristics are presented in fig. 1 and fig. 2 . 
Strength analyses were carried out in two variants of both models. In the linear model, different values of rigidity modulus and Poisson's coefficient were used (each material had two values given in the first and second main directions): maximum $(H 1)$, minimum $(H 2)$ and average (Hśr). Autodesk Helius PFA software was used to transfer linear material properties.

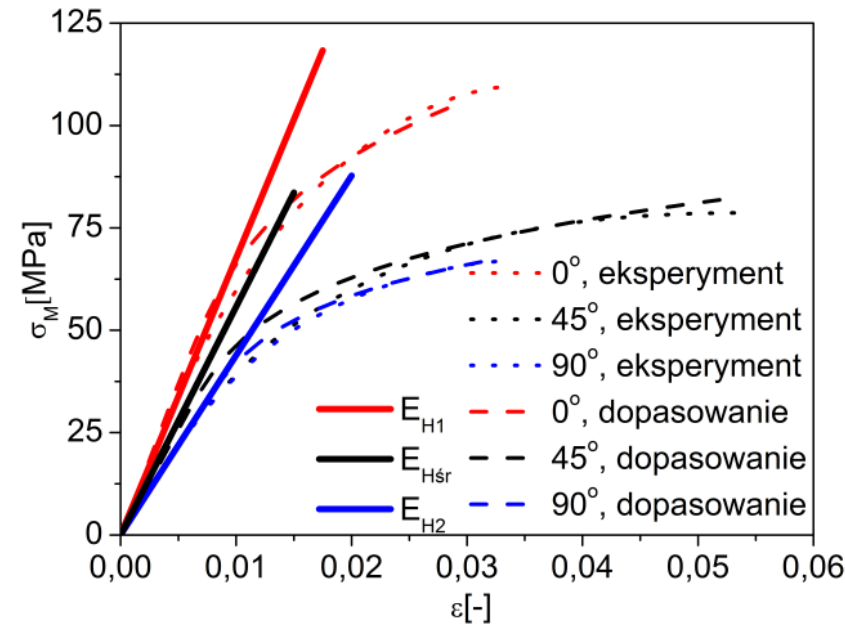

Fig. 1. Material characteristics of POM25 [7]. Experiment experimental curve; fit - curve tailored to the RO model, used in simulations; $E_{H}$ - dependence according to Hooke's law; $0^{\circ}, 45^{\circ}$, $90^{\circ}$ - angles at which samples were cut in relation to the orientation of the fibers

\section{Eksperyment - Experiment \\ Dopasowanie - Fit}

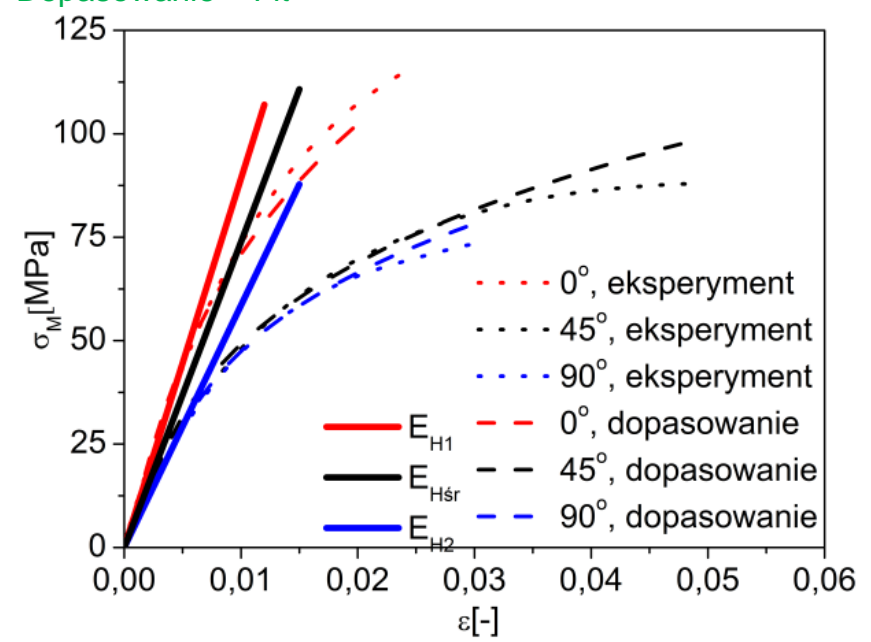

Fig. 2. Material characteristics of POM35 [7]. Experiment experimental curve; fit - curve tailored to the $\mathrm{RO}$ model, used in simulations, $E_{H}$ - dependence according to Hooke's law; $0^{\circ}, 45^{\circ}$, $90^{\circ}$ - angles at which samples were cut in relation to the orientation of the fibers

The first example $(P 1)$ was a piece of a plate used to test the mechanical properties of fiber-filled plastics. A dray cut in the perpendicular direction $(\perp)$ and parallel to the direction of fiber orientation (II) was used for the simulation. The distribution of the fiber orientation in the plate to be injected and the cut holes are shown in fig. 3 . The element was subjected to uniaxial stretching, where the sample elongation was $5 \mathrm{~mm}$. a)

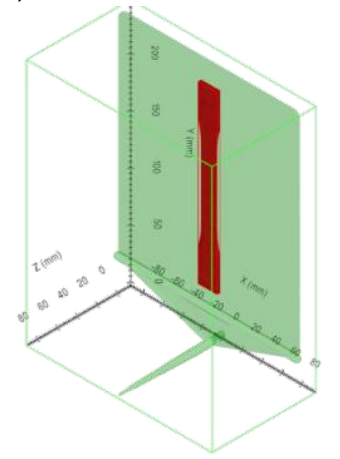

b)

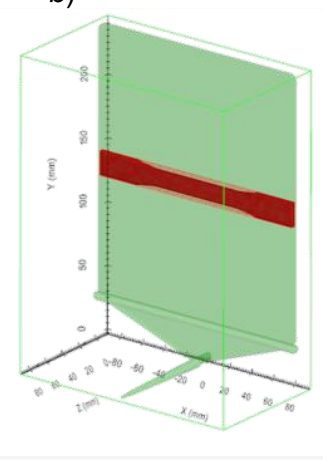

Fig. 3. Element $P 1$ oriented in the direction: a) parallel and b) perpendicular to the orientation of the fibers

The second example (P2) was the brake pedal. The analysis was carried out with one injection point placed at one end. If the appropriate material data are available, it is possible to automatically determine the strength of individual lines. For the purposes of the analysis, the possibility of movement of the part on the shafts and in its lower part was blocked as well as all degrees of freedom on the chamfered part were received. Perpendicular force of $500 \mathrm{~N}$ was applied to the surface of the pedal.

\section{Results}

Fig. 4 presents the results - the first two strain maps show a clear difference in the magnitude of strain (4a-b). In the case of the RO model, a greater deformation in the central part and less deformation in the wider areas were observed. This is important, because the displacement was applied to the upper and lower extremities of the sample. The stresses calculated according to Hooke's law had a distribution as for $\mathrm{RO}$, but the minimum and maximum values were different. On the last paddle (fig. $4 d$ ), it can be seen a significant reduction in the rigidity of the element in the central part at the end of stretching, which cannot be predicted with the use of Hooke's law. The list of tested parameters for various material models for $P 1$ is presented in the Table I.

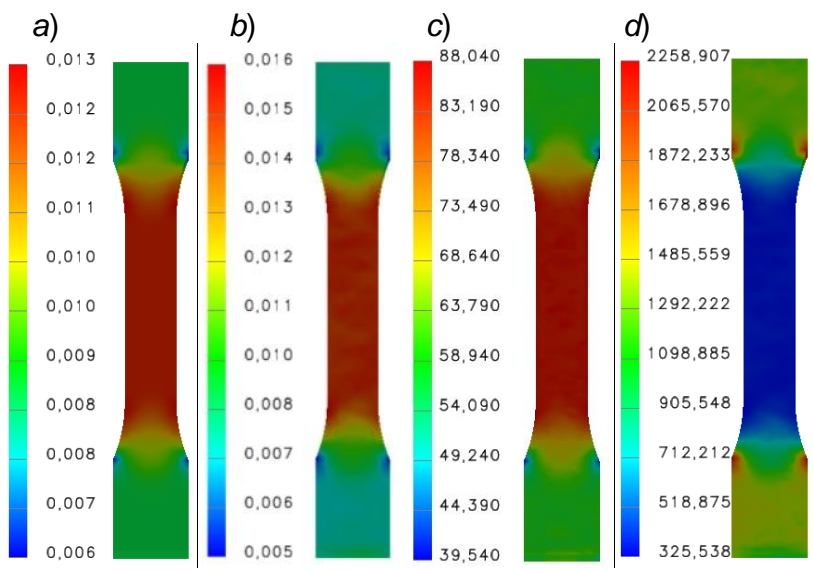

Fig. 4. Deformation according to Hooke's law $\varepsilon_{H 1}$ (a); deformation according to the RO $\varepsilon_{R O}$ model (b); stresses $\sigma_{m}$ in $\mathrm{MPa}$ (c); tangent rigidity modulus $E_{T}$ in MPa before destruction of the $P 1$ specimen oriented along the fibers (from the left) for POM25 (d)

In the first part of the Table I, the results obtained from the RO model and Hooke's law were included. The 
results coincide with the data presented in fig. 1 and fig. 2. With the increase of fiber content, the maximum deterioration of the rigidity of the element in the central part decreases. For deformation of the sample according to fig. 2, similar maximum displacements $\Delta l$ of both materials were observed.

\section{TABLE I. List of parameters tested for $P 1$}

\begin{tabular}{|c|c|c|c|c|}
\hline \multirow{2}{*}{ Material } & \multirow{2}{*}{$\begin{array}{l}\sigma_{M}[M P a] \\
\operatorname{Min} / \max \end{array}$} & \multirow{2}{*}{$\Delta l_{\max }[\mathrm{mm}]$} & \multicolumn{2}{|c|}{$E_{R O}[M P a]$} \\
\hline & & & $\Delta l=0$ & Min./max. \\
\hline POM25॥ & $39,54 / 88,04$ & 2,15 & 2411,63 & $325,5 / 2259$ \\
\hline POM25」 & $34,75 / 65,53$ & 3,35 & 2411,63 & $226,6 / 2103,3$ \\
\hline POM35॥ & $32,61 / 80,87$ & 1,35 & 3004,51 & $325,5 / 2075$ \\
\hline POM35」 & $40,34 / 73,76$ & 3,25 & 3004,51 & $306,4 / 1496$ \\
\hline \multirow[t]{3}{*}{ Material } & \multicolumn{2}{|c|}{ POM25 } & \multicolumn{2}{|c|}{ POM35 } \\
\hline & $\begin{array}{l}\sigma_{M}[M P a] \\
\left(\Delta l_{\max }\right)\end{array}$ & $\begin{array}{l}\sigma_{M}[M P a] \\
(\Delta l=5)\end{array}$ & $\begin{array}{l}\sigma_{M}[M P a] \\
\left(\Delta l_{\max }\right)\end{array}$ & $\begin{array}{l}\sigma_{M}[M P a] \\
(\Delta l=5)\end{array}$ \\
\hline & $\operatorname{Min} / \max$ & $\operatorname{Min} / \max$ & $\operatorname{Min} / \max$ & $\operatorname{Min} / \max$ \\
\hline$E_{l i n \|}$ & $43,7 / 103$ & $101,5 / 239,4$ & $36,7 / 89,6$ & $135,9 / 331,5$ \\
\hline$E_{\operatorname{lin} \perp}$ & $43,2 / 84,7$ & $64,5 / 126,4$ & $50 / 97,5$ & $77,2 / 150$ \\
\hline$E_{H 1}$ & $48,2 / 99,3$ & $112 / 230$ & $39,9 / 82,6$ & $147,6 / 304,6$ \\
\hline$E_{H 2}$ & $48,9 / 100,4$ & $73 / 150$ & $63,2 / 130$ & $97,3 / 199,9$ \\
\hline $\begin{array}{c}E_{a v}(\|) \\
E_{a v}(\perp)\end{array}$ & $\begin{array}{c}39,7 / 81,9 \\
61,9 / 127,6\end{array}$ & $92,4 / 190,4$ & $\begin{array}{l}33,1 / 68,1 \\
79,6 / 164\end{array}$ & $122,4 / 252,3$ \\
\hline
\end{tabular}

a)

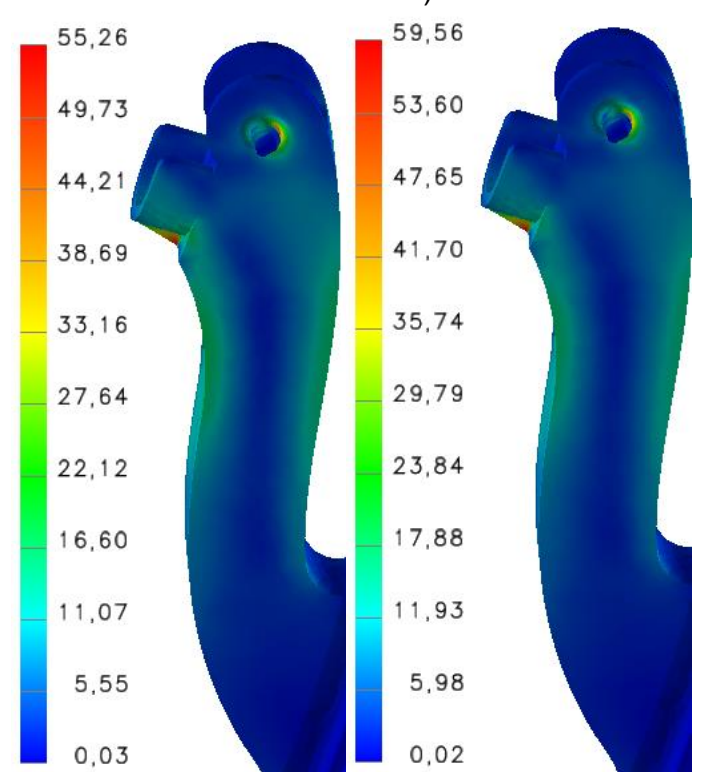

Fig. 5. Stresses $\sigma_{m}$ in MPa for: a) POM25 and b) POM35 according to the $\mathrm{RO}$ model

Based on the comparison of results with the Hooke's law, the stress value for the maximum $\Delta I_{\max }$ displacement and the boundary conditions, was determined. In the case of $\Delta I_{\max }$, the best accuracy was obtained after linearization using the Autodesk Helius software $\left(E_{\text {lin }}\right)$ and after applying the averaged value of the $E_{a v}$ rigidity modulus (but only with the parallel arrangement of the fibers). For the maximum displacement, more than twice the stresses were obtained than in the RO model, which were admissible values from the point of view of

displacements (the sample length was $176.72 \mathrm{~mm}$, thus a displacement of $5 \mathrm{~mm}$ occurs with uniform strain of the sample at 0.028 ). For this reason, without a simulation showing the distribution of the deformation of the sample and taking into account its destruction, predicting the correct behavior of the elements filled with fiber is very difficult.

In the case of $P 2$, slight differences in the stresses between the materials were observed (fig. 5, Table II) the bottom rib and the chamfered shaft were analyzed. On the other hand, the plastic type had a very pronounced effect on the rigidity and maximum displacement of the loaded compact. In the case under consideration, the results obtained on the basis of the Autodesk Helius data linearization are characterized by good accuracy - too large values were obtained in the case of a rib. The disadvantage of this solution was practically twice as large displacement compared to the RO model.

In the assumption of a linear material consistent with Hooke's law, the stress value for the rib had a very good convergence, but in the case of shear within the shaft, the program predicted much higher stresses. The best deformation mapping was observed when the rigidity modulus conforming to the first main direction was used the deformations were not much smaller than for the RO.

\section{TABLE II. List of tested parameters for $P 2$}

\begin{tabular}{|c|c|c|c|c|}
\hline \multirow{2}{*}{ Material } & \multicolumn{2}{|c|}{ POM25 } & \multicolumn{2}{c|}{ POM35 } \\
\hline & $\begin{array}{c}\sigma_{M}, M P a \\
\text { rib/roller }\end{array}$ & $\Delta l, \mathrm{~mm}$ & $\begin{array}{c}\sigma_{M}, M P a \\
\text { rib/roller }\end{array}$ & $\Delta l, \mathrm{~mm}$ \\
\hline$E_{R O}$ & $59,6 / 49,5$ & 4,22 & $55,3 / 49,8$ & 3,127 \\
\hline$E_{\text {lin }}$ & $68 / 46,4$ & 7,02 & $73 / 47,5$ & 6,096 \\
\hline$E_{H 1}$ & $54 / 76$ & 3,9 & $55 / 77,2$ & 2,96 \\
\hline$E_{H 2}$ & $52 / 63$ & 5,89 & $50,6 / 61,3$ & 4,41 \\
$E_{a v}$ & $52,5 / 70,8$ & 4,7 & $54,7 / 71,9$ & 3,55 \\
\hline
\end{tabular}

a)

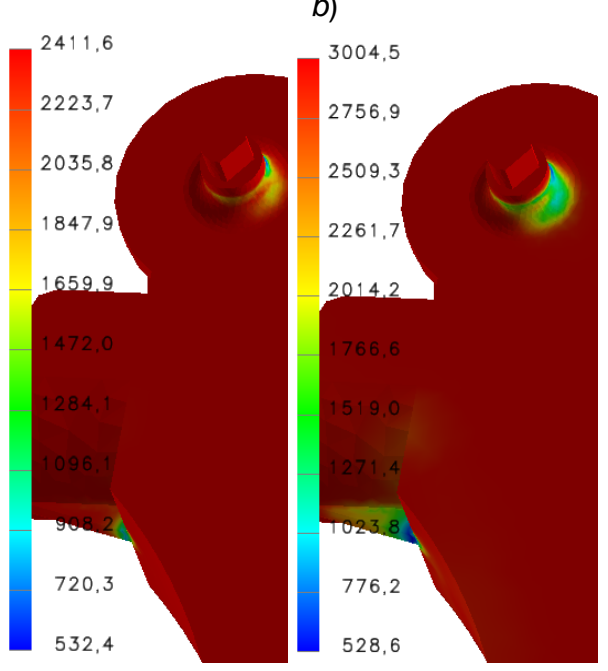

Fig. 6. Tangent rigidity modulus $E_{T}$ in MPa for: a) POM25 and b) POM35

Fig. 6 shows the changes in the tangent rigidity modulus, where along with the increase in the reinforcing fiber content, the value of rigidity in the area of the 
chamfered roller and the rib has increased. However, it was observed that the minimum rigidity value was similar in both cases.

The use of $\mathrm{RO}$ model also allows to predict the amount of plastic deformation. In the $P 2$ model, plastic deformations amounted to approximately 0.009 , which means that for the assumed load, the compact should be redesigned to prevent permanent deformation.

\section{Conclusions}

The linear model (Hooke's law) allowed good representation of the deformation of the element when the applied force was the load. The highest accuracy was obtained using a rigidity module determined parallel to the direction of the $E_{H 1}$ fiber orientation. The displacement was slightly less than the displacement obtained for the RO model. The use of the average rigidity modulus $E_{a v}$ gave much less accurate results than $E_{H 1}$. In the case studied, the application of Hooke's law allowed for a good reproduction of stresses due to compression and deformation in the direction of the fiber orientation. On the other hand, it was definitely less accurate in the case of shearing and stretching.

The application of the Autodesk Helius linear deformation module allowed for a much better stress pattern in the case of stretching and shearing (greater discrepancy was observed in compression). On the other hand, when bending, the module indicated a twice larger displacement than obtained for the non-linear model and gave worse results than the application of Hooke's law.

\section{REFERENCES}

1. Fu S.-Y., Lauke B., Mader E., Yue C.-Y., Hu X. "Tensile properties of short glass fiber- and short carbon fiber reinforced polypropylene composite.Composites: Part A. 31 (2000): s. 117-1125, doi: 10.1016/S1359-835X(00)00068-3.

2. Karta katalogowa Lyondell Basell Hostacom PPN 1060.

3. Bakar M. „Właściwości mechaniczne polimerów”. Radom Wydawnictwo Politechniki Radomskiej, 2009.

4. Nguyen B.N., Bapanapalli S.K., Kunc V., Phelps J.H., Tucker III C.L. "Prediction of the elastic-plastic stress/strain response for injection-molded long-fiber Thermoplastics". Journal of Composite Materials. 43, 3 (2009): s. 217-246, doi: 10.1177/0021998308099219.

5. Ramberg W., Osgood W.R. "Description of stress-strain curves by three parameters". Technical Note. 902. Washington DC: National Advisory Committee For Aeronautics, 1943.

6. Dokumentacja programu Autodesk Helius PFA 2018.

7. Autodesk Inc. "Autodesk Moldflow Insight". San Rafael, CA. 94903, USA, 2017. 